\title{
Clinical prediction rule for return to work after back pain
}

\section{Christopher Maher}

ß See related article page 1559

$\mathrm{B}$ ack pain is the main cause of work absence and disability in industrialized societies, and one of the most common reasons for a visit to a physician. ${ }^{1}$ Effective treatments for workers with back pain range in complexity and cost from simple advice and reassurance, ${ }^{2}$ through exercise programs, ${ }^{3}$ to functional restoration programs that involve 4-6 weeks of full-time multidisciplinary treatment. ${ }^{4}$ The more expensive treatments are usually reserved for workers who are believed to have a poor prognosis; however, this approach presumes that it is possible to reliably identify these individuals.

A large number of studies have attempted to identify predictors of poor outcome in people with back pain. The most consistently identified predictors are psychosocial; for example, mood, thoughts and feelings about the person's back pain and the perceived support from workplace and family. ${ }^{5}$ Combining single predictors to develop an algorithm for identifying workers with a high risk for poor outcome has been attempted less often, and rarely done well. That is why Dionne and colleagues' study ${ }^{6}$ is important (see page 1559).

Dionne's group enrolled a prospective cohort of 1007 consecutive workers with back pain presenting to primary care, collected data on potential predictors at baseline and then followed the workers for 2 years. The constructs measured as potential predictors were very broad and included sociodemographic, anthropometric, health behaviour, clinical, occupational and psychological factors. A successful return-to-work outcome required the worker to be at his or her normal job with minimal recent work absences and minimal disability. The authors then used recursive partitioning to develop a clinical prediction rule that can be used to identify workers at risk of poor outcome. The 7 predictors were the patient's expectations of recovery, radiating pain, previous back surgery, pain intensity, frequent changes of position because of back pain, irritability and bad temper, and difficulty sleeping.

This study is significant because it is the first to both derive and validate a clinical prediction rule for identifying those at high risk of a poor occupational outcome. The study is also important because the authors measured return to work in a more meaningful way than usual. Too often, researchers have measured return to work on a yes/no scale, ${ }^{7}$ which may be simple for data collection and analysis but ignores the reality that return to work in good health is a multidimensional construct. The return-to-work goal should arguably be durable return with no functional limitations, which is what is reflected in Dionne and colleagues' definition of a successful outcome. The study had good follow-up, and because classification error rates of the final predictive model were similar between the derivation and validation samples, the obtained solution seems robust.

Unfortunately, the algorithm overall is not as accurate as we might wish. Its classification error rate is about $40 \%$, which is only a little more accurate than simply advising all patients that their prognosis is good - the advice in most guidelines for managing lower-back pain. ${ }^{8}$ Because the prevalence of success at 2 years in the Dionne group's sample was about $55 \%$, a strategy of telling all patients that they will recover would produce a classification error rate of $45 \%$. However, other clinical algorithms often do no better than this. The classification error rates of the best-known tool, the Orebro Musculoskeletal Pain Questionnaire, ${ }^{9}$ is $20 \%-30 \%$ for prediction of recovery of function, for example, and $30 \%-$ $50 \%$ for prediction of pain recovery. Dionne and colleagues considered all constructs known or believed to be important prognostic factors, so it is unclear why better prediction was not achieved. Our current understanding about back pain perhaps makes more accurate prediction impossible.

Although overall the algorithm is not that accurate, the negative predictive value was much higher than the positive predictive value, meaning that the algorithm is much better at predicting those who will not have a poor outcome than those who will. Moreover, there are individual decision pathways within the algorithm where classification error appears to be small, which means that accurate prediction may be possible for some workers. The authors have provided some examples in Fig. 3; however, a note of caution is essential. Extrapolation of the predictive values in Fig. 3 is meaningful only in groups of patients with similar prevalences; this is because, as noted in a footnote to their Table 3 , positive and negative predictive values of tests are influenced by the prevalence of the underlying disorder. ${ }^{10}$ If Dionne and colleagues had provided counts rather than percentages, likelihood ratios could be derived that would allow clinicians to quickly generate patient-specific estimates of prognosis using a simple nomogram. This would allow the algorithm to be used in patient populations 
among which the probability of return to work differs from that in the study under discussion.

Can this or other algorithms assist treatment selection? The authors suggest that the algorithm can be used in deciding the best allocation of clinical resources for patients with back pain, and they provide some examples. The rationale is that more extensive multidisciplinary treatment should be reserved for those at high risk of a poor outcome. Although this treatment approach appears sensible, Dionne's group provides no direct data to support the suggestions. One study, however, does provide some data to confirm the treatment suggestions provided by the authors: Haldorsen and coauthors ${ }^{11}$ randomly assigned employees sick-listed for a long period to receive usual care or a brief or extensive multidisciplinary program. Consistent with the treatment suggestions of Dionne and colleagues, those classified as having a high risk for a poor outcome did much better with an extensive multidisciplinary treatment, whereas for those with a good prognosis, the 3 treatments showed equal effectiveness. It would make sense to offer these patients the simpler and cheaper management options. Unfortunately, there are no other studies like that of Haldorsen's group, and further evaluation of this issue is therefore required.

Christopher Maher is an Associate Professor at the School of Physiotherapy, University of Sydney, Lidcombe, Australia.

Competing interests: None declared.

\section{References}

1. Mounce K. Back pain. Rheumatology 2002;41:1-15

2. Indahl A, Velund L, Reikeraas O. Good prognosis for low back pain when left untampered: a randomised clinical trial. Spine 1995;20(4):473-7.

3. Lindstrom I, Ohlund C, Eek C, Wallin L, Peterson LE, Fordyce WE, et al The effect of graded activity on patients with subacute low back pain: a randomised prospective clinical study with an operant-conditioning behavioral approach. Phys Ther 1992;72(4):279-93.

4. Bendix A, Bendix T, Lund C, Kirkbak S, Ostenfeld S. Comparison of three intensive programs for chronic low back pain patients: a prospective, randomized, observer-blinded study with a one-year follow-up. Scan 7 Rebab Med 1997;29(2):81-9.

5. Linton SJ. A review of psychological risk factors in back and neck pain [review]. Spine 2000;25(9):1148-56.

6. Dionne CE, Bourbonnais R, Frémont P, Rossignol M, Stock SR, Larocque I A clinical return-to-work rule for patients with back pain. CMA7 2005;172 (12):1559-67.

7. Coste J, Delecoeuillerie G, Cohen de Lara A, Le Parc JM, Paolaggi JB. Clinical course and prognostic factors in acute low back pain: an inception cohort study in primary care practice. BMF 1994;308(6928):577-80.

8. Koes B, van Tulder M, Ostelo R, Burton A, Waddell G. Clinical guidelines for the management of low back pain in primary care: an international comparison. Spine 2001;26(22):2504-14.

9. Linton SJ, Boersma K. Early identification of patients at risk of developing a persistent back problem: the predictive validity of the Orebro Musculoskeletal Pain Questionnaire. Clin 7 Pain 2003;19(2):80-6.

10. Grimes DA, Schulz KF. Defining clinical diagnosis with likelihood ratios. Lancet 2005;365:1500-5.

11. Haldorsen EM, Grasdal AL, Skouen JS, Risa AE, Kronholm K, Ursin H. Is there a right treatment for a particular patient group? Comparison of ordinary treatment, light multidisciplinary treatment, and extensive multidisciplinary treatment for long-term sick-listed employees with musculoskeletal pain. Pain 2002;95:49-63.

Correspondence to: Dr. Christopher Maher, School of Physiotherapy, Building C42, Faculty of Health Sciences, University of Sydney, PO Box 170, Lidcombe NSW 1825,

Australia; fax 612 93519601; c.maher@fhs.usyd.edu.au

\section{CMA Centre for Physician Health
and Well-being
Adyancing Leadership in Physician Health}

23-24 September 2005

Hilion Toronto, Toronto, Ont.

PROFESSIONAL DEYELOPWENT PROGR AM

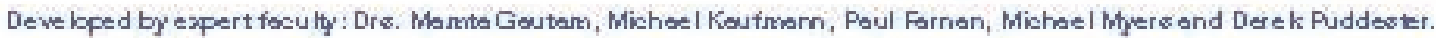

Giving physician keaders the skills, tools and resources to promote and protect their own health and that of their physician colleagues.

Phyeicians with en interest in, orz mendzte bo, promote the wellnes of colleagues will derabp an understanding of the risk factors and spocial nosts of phyei-iars, learn to rsoognim iik situations and rspond sffertively undes and how to areste and mainteinan ensionment that promots the wrltbeing of their collsagus. and desebp pesonel hes th skills that allow them to thriese in their coner and ares te belenes in their life.
Adrancing Leaderehip in Physiain Health an ato be brought to you as anir-house progrem and designod sporifially for your organtation.

Register now!

Contact the CWLA Centre for Physieian Helth and Welt-being 2t $800663-7336 \times 2877$ or $613731-8610$ 2877; senyurgthut arrea or wis it the centre loatsd ancree. $R$.

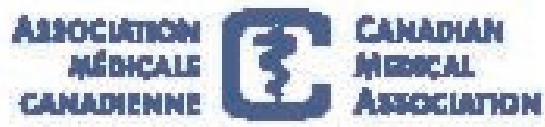

